\title{
Indian promise
}

\section{A biotechnology boom in India is attracting the interest of manufacturers of imaging equipment who now recognize the country as an important emerging market.}

\section{Oliver Graydon \\ Nature Photonics, Chiyoda Building, 2-37 Ichigayatamachi, Shinjuku-ku, Tokyo 162-0843, Japan.}

e-mail: o.graydon@natureasia.com

R esearch into biotechnology in India has been given a recent boost with the creation of a new centre in Bangalore dedicated to microscopy and biological imaging. The Micro-Imaging Center is a partnership between India's National Center for Biological Sciences (NCBS) and Olympus, the Japanese manufacturer of optical and digital imaging equipment (see Business News on page 636).

The motivation behind the deal is simple to understand and a potential winwin situation for both parties. Olympus loans the centre its latest microscopy imaging systems in an attempt to raise its brand awareness and user-base in India, and scientists from NCBS and visiting staff from elsewhere in the country receive access to state-of-the-art equipment.

Established in 1991, NCBS is one of India's leading and largest research institutes dedicated to biology and is part of the Tata Institute of Fundamental Research. It is home to around 300 staff and carries out research ranging from investigation into biomolecules and cell processes through to animal models and systems biology.

The new $77 \mathrm{~m}^{2}$ centre, located on the NCBS campus, opened on 1 September and almost all the equipment is now in place, according the centre's director Satyajit Mayor, who is also an active researcher at NCBS. Once fully equipped, the centre will house a live cell imaging station, a total-internal-reflection fluorescence microscope system, a disk-scan confocal microscope, a fluorescence macromicroscope and a fluorescence stereomicroscope. All the equipment is supplied as a two-year loan from Olympus.

"Five major pieces of equipment are now in place and the sixth, the laser confocal microscope, is due very soon," said Mayor. "There is a strong emphasis on fluorescence imaging equipment as NCBS has a very strong background in this area." As well as aiding research, the centre will also host training programs, workshops and seminars

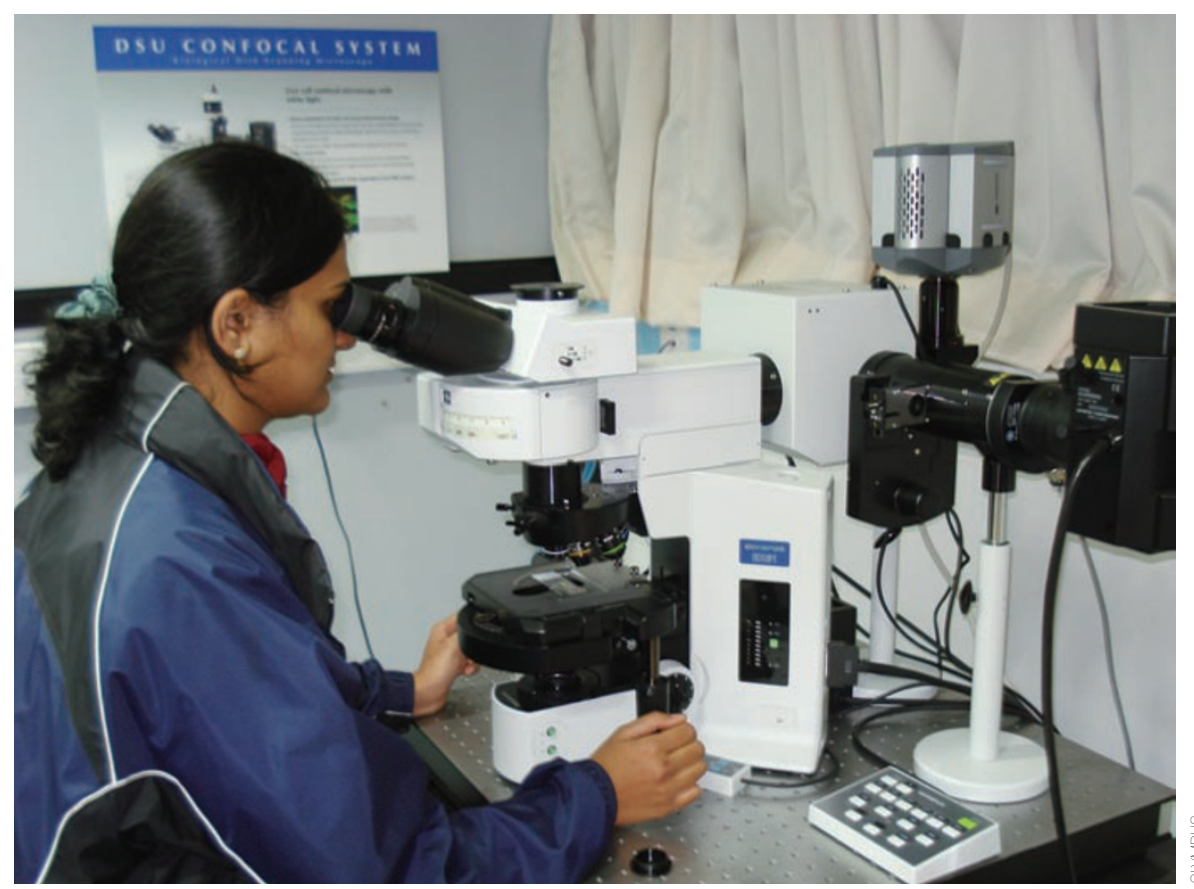

Look inside: A view of the interior of the Micro-Imaging Center facilities in Bangalore.

to educate researchers in the use of the latest imaging equipment. In fact the first workshop is scheduled to take place in the next few weeks.

The deal highlights the growing importance of the Indian biotechnology sector, especially as an emerging market for medical imaging companies, such as Olympus, Nikon and Zeiss. In 2005, the Indian government announced a 'National Biotechnology Development Strategy'. Thanks to this directive and inward investment from foreign firms, India is forecast to build a biotechnology industry capable of generating an income of $\$ 5$ billion and one million jobs by 2010 . "There has been a huge influx of funding into science and biotechnology in India," explained Mayor. "Imaging and photonics is on its ascent but for a long time we didn't have the local support from manufacturers."

Olympus certainly believes the future is bright for India and that it will become a major player in the global biotechnology sector. "For the past 10 years, IT has been the driving force behind the Indian economy, but biotechnology is now an important second pillar for supporting growth," explained Takashi Hattori from Olympus's Micro-Imaging Systems Division in Singapore. "Lots of pharmaceutical companies, including all the major US and European firms, have now set up facilities in India and it's becoming an increasingly important source of potential customers."

The centre will initially run as a twoyear trial, and its achievements will then be assessed before any further investment. If all goes well, Olympus would then consider the loan of further equipment and perhaps even the opening of another facility in the north of the country.

"All the installed systems are new Olympus products to the market, but as the next level of engagement they could look at using us as a beta-test facility for new technologies," said Mayor. "We will have this two-year test run and take it from there." 